\title{
DETECTION OF PULMONARY SHUNTS BY TRANSCRANIAL DOPPLER IN HOSPITALIZED NON-MECHANICALLY VENTILATED CORONAVIRUS DISEASE-19 PATIENTS
}

\author{
Jaime L. I. Salazar-Orellana ${ }^{1}$, Miguel García-Grimshaw ${ }^{1}$, Sergio I. Valdés-FerreR ${ }^{1,2}$, \\ Sergio M. Alday-Ramírez ${ }^{3}$, Eduardo Ríos-Argaiz ${ }^{3}$, Zuilma Y. VÁsquez-Ortiz ${ }^{4}$, \\ Eduardo Rivero-Sigarroa ${ }^{5}$, Amado Jiménez-Ruiz ${ }^{6}$, Erwin Chiquete ${ }^{1}$, Carlos Cantú-Brito ${ }^{1}$, \\ AND FERNANDO D. FLORES-SILVA ${ }^{1 *}$ \\ ${ }^{1}$ Department of Neurology and Psychiatry, Instituto Nacional de Ciencias Médicas y Nutrición Salvador Zubirán \\ (INCMyNSZ), Mexico City, Mexico; ${ }^{2}$ Center for Biomedical Science, Feinstein Institute for Medical Research, \\ Manhasset, New York, USA; Departments of ${ }^{3}$ Internal Medicine; ${ }^{4}$ Cardiology, and 5 Intensive Care, INCMyNSZ, \\ Mexico City, Mexico; ${ }^{6}$ Stroke, Dementia \& Heart Disease Laboratory, Western University, London, Ontario, \\ Canada
}

\section{BACKGROUND}

In severe acute respiratory syndrome coronavirus 2 (SARS-CoV-2)-associated disease coronavirus disease 2019 (COVID-19), hypoxemia mechanisms differ from those observed in acute respiratory distress syndrome. Hypoxemia and respiratory failure in COVID-19 are attributed to pulmonary angiopathy, increasing physiological pulmonary shunting ${ }^{1-3}$. Contrast-enhanced transcranial Doppler (TCD) with agitated saline of middle cerebral arteries (MCA) is a non-invasive method with a higher sensitivity for detecting right-to-left shunts than contrast-enhanced echocardiography ${ }^{4}$. TCD has been used to detect intrapulmonary shunts in COVID-19 patients undergoing invasive mechanical ventilation $(I M V)^{5}$. We studied the relationship between intrapulmonary shunting, disease severity, and in-hospital outcome in COVID-19 patients not undergoing IMV (nonIMV).

\section{METHODS}

We conducted a prospective observational study at Instituto Nacional de Ciencias Médicas y Nutrición Salvador Zubirán from September 7, 2020, to October 14, 2020, including consecutive hospitalized, nonIMV adult ( $\geq 18$ years) patients presenting during the first 10 days from symptom onset, with a positive SARS-CoV-2 real-time polymerase chain reaction test from nasal swab samples, and a COVID-19 compatible chest computed tomography (CT) scan. We excluded patients transferred to other hospitals within
*Corresponding author:

Fernando D. Flores-Silva

E-mail: ferfs98@gmail.com
Received for publication: 19-11-2020

Approved for publication: 07-12-2020

DOI: 10.24875/RIC.20000569

0034-8376 / (c) 2020 Revista de Investigación Clínica. Published by Permanyer. This is an open access article under the CC BY-NC-ND license (http://creativecommons.org/licenses/by-nc-nd/4.0/). 
the first $24 \mathrm{~h}$ after admission; those with a known history of pulmonary, liver, or structural heart disease; and patients undergoing hemodialysis or extracorporeal membrane oxygenation. The Institutional Research and Ethics Committees approved the conduction of the study (NER-3401-20-20). Signed informed consent was obtained from each patient.

We captured demographic characteristics, comorbidities, clinical information, chest CT scan, and laboratory findings in a database derived from electronic medical records. Lung involvement by chest CT-scan was semi-quantitatively classified as mild/moderate (20-50\%) or severe ( $>50 \%$ ) by experienced radiologists. We calculated the $\mathrm{PaO}_{2} / \mathrm{FiO}_{2}$ ratio using the $\mathrm{FiO}_{2}$ provided by each oxygen delivery device (nasal cannula or simple face mask) when arterial blood gases (ABGs) were obtained.

In all patients, we performed a contrast-enhanced TCD of both MCA within the first 3 days after admission with a portable Digi-One ${ }^{\mathrm{TM}}$ ultrasound (Rimed Inc., NY, USA) using a $2 \mathrm{MHz}$ transducer at an insonation level of 45-55 mm. Agitated saline was injected through a peripheral intravenous line in the upper extremity. The system software automatically counted the number of high-intensity signals (HITS), defined as unidirectional signals of a duration of $<300$ ms, with an amplitude of at least $3 \mathrm{~dB}$ greater than the background blood flow signal, within the Doppler spectrum and accompanied by a characteristic sound, during a 10-s Valsalva maneuver, which two researchers later manually validated. We performed a contrast-enhanced transthoracic echocardiogram in patients with a positive test to rule out right-to-left cardiac shunts.

We compared the characteristics and outcomes of patients with pulmonary shunts and those without shunts. Categorical variables are reported as frequencies and proportions. Continuous variables as the median with interquartile range (IQR) or as mean with $\mathrm{SD}$. Analyses of differences between categorical variables were performed with the $\mathrm{X}^{2}$ test and for continuous variables with the Student's t-test or MannWhitney U-test. Associations between the number of HITS, days of illness, $\mathrm{PaCO}_{2}$ levels, and $\mathrm{PaO}_{2} / \mathrm{FiO}_{2}$ ratio were performed by simple linear regression. All values were two-tailed and considered significant when $p \leq 0.05$. Statistical analyses were performed with IBM SPSS Statistics, version 26 (IBM Corp., Armonk, NY, USA).

\section{RESULTS}

We studied 31 patients ( $87.5 \%$ men, and mean age: $44.4 \pm 11.02$ years). Eight patients had a positive HITS test; one patient was diagnosed with a patent foramen ovale, and 7 (22.5\%) with pulmonary shunts. The median interval from symptom onset to admission was 7 days. There were no differences in demographics, comorbidities, ABG analysis, and chest $\mathrm{CT}$ findings between patients with and those without pulmonary shunts (Table 1 ). Patients with a positive HITS test had higher D-dimer and lower C-reactive protein levels. The median number of HITS was 5 (IQR: 3-11). There was no relationship between the number of $\mathrm{HITS}, \mathrm{PaCO}_{2}$ levels, $\mathrm{PaO}_{2} / \mathrm{FiO}_{2}$ ratio, or interval from symptom onset to admission (Fig. 1). At admission, all patients received intravenous dexamethasone ( $6 \mathrm{mg} /$ day for 5-10 days) and thromboprophylaxis with either unfractionated heparin or enoxaparin before TCD was performed. None of the patients were receiving vasopressors or had a diagnosis of pulmonary bacterial coinfection when the TCD was performed. Five patients required IMV after TCD was performed (none with a positive HITS test). The number of days of in-hospital stay and outcome was similar between groups.

\section{DISCUSSION}

In this study, we detected intrapulmonary shunts in $22.5 \%$ of non-IMV patients with COVID-19. In contrast to the $83 \%$ of right-to-left shunts from an undetermined source described in COVID-19 patients undergoing IMV, in which the $\mathrm{PaO}_{2} / \mathrm{FiO}_{2}$ ratio correlated with the number of $\mathrm{HITS}^{5}$, we did not observe this correlation. Disease severity by chest CT scan and $\mathrm{PaO}_{2} / \mathrm{FiO}_{2}$ ratio was similar between groups, but D-dimer levels were higher in patients with pulmonary shunts. These findings suggest that vascular pathology develops during the mild-to-moderate stages of COVID-19, probably due to microthrombosis and occlusion of alveolar capillaries ${ }^{1,3}$. Interestingly, none of the patients with a positive HITS test required IMV, and mortality rates were similar between groups, 
Table 1: Baseline characteristics and in-hospital outcomes of COVID-19 patients

\begin{tabular}{|c|c|c|c|c|}
\hline & $\begin{array}{l}\text { All patients } \\
\quad(n=31)\end{array}$ & $\begin{array}{l}\text { Without pulmonary } \\
\text { shunts } \\
(n=24)\end{array}$ & $\begin{array}{l}\text { With pulmonary } \\
\text { shunts } \\
(n=7)\end{array}$ & p-value \\
\hline Age, mean ( $\pm S D)$, years & $44.4(11.02)$ & $43.83(10.37)$ & $46.14(13.83)$ & 0.412 \\
\hline Sex, n (\%), male & $25(80.6)$ & $21(87.5)$ & $4(57.1)$ & 0.074 \\
\hline \multicolumn{5}{|l|}{ Comorbidities, n (\%) } \\
\hline Diabetes & $6(19.4)$ & $5(20.8)$ & $1(14.3)$ & 0.7 \\
\hline Hypertension & $7(22.6)$ & $5(20.8)$ & $2(28.6)$ & 0.667 \\
\hline Smoking & $18(58.1)$ & $16(66.7)$ & $2(28.6)$ & 0.072 \\
\hline Chronic kidney disease & $3(9.7)$ & $1(4.2)$ & $2(28.6)$ & 0.055 \\
\hline Obesity, BMI $\geq 30 \mathrm{~kg} / \mathrm{m}^{2}$ & $13(41.9)$ & $10(41.7)$ & $3(42.9)$ & 0.955 \\
\hline BMI, mean $( \pm S D), \mathrm{kg} / \mathrm{m}^{2}$ & $30.66(7.91)$ & $30.67(7.38)$ & $30.63(10.19)$ & 0.991 \\
\hline $\begin{array}{l}\text { Days from symptom onset, } \\
\text { median (IQR) }\end{array}$ & $7(5-8)$ & $7(6-8)$ & $6(2-8)$ & 0.199 \\
\hline \multicolumn{5}{|c|}{ Inflammatory response biomarkers, median (IQR) } \\
\hline D-dimer, ng/dL & $639(462-961)$ & $594(444-747)$ & $1005(800-1767)$ & 0.017 \\
\hline Lactic dehydrogenase, $\mathrm{U} / \mathrm{L}$ & $305(239-354)$ & $310.5(243.5-376.5)$ & $261(220-317)$ & 0.317 \\
\hline Ferritin, ng/dL & $522.6(332.3-806.8)$ & $570.7(317-1335.6)$ & $491.2(332.3-621.8)$ & 0.417 \\
\hline C-reactive protein, $\mathrm{mg} / \mathrm{dL}$ & $12.39(5.87-20.01)$ & $15.93(8.32-21.65)$ & $5.49(3.26-11.63)$ & 0.017 \\
\hline Neutrophil/lymphocyte ratio & $6.7(4.49-10.62)$ & $6.45(4.55-9.89)$ & $9.93(3.86-14.73)$ & 0.563 \\
\hline \multicolumn{5}{|l|}{ ABGs, mean ( $\pm S D)$} \\
\hline $\mathrm{pH}$ & $7.45(0.047)$ & $7.45(0.05)$ & $7.45(0.06)$ & 0.882 \\
\hline $\mathrm{PaO}_{2}, \mathrm{mmHg}$ & $73.25(20.23)$ & $72.06(21.92)$ & $77.34(13.39)$ & 0.552 \\
\hline $\mathrm{PaCO}_{2}, \mathrm{mmHg}$ & $30.96(4.15)$ & $30.69(4.27)$ & $31.89(3.9)$ & 0.513 \\
\hline $\mathrm{HCO}_{3}-, \mathrm{mmol} / \mathrm{L}$ & $21.62(2.95)$ & $21.48(3.09)$ & $22.11(2.54)$ & 0.624 \\
\hline $\mathrm{PaO}_{2} / \mathrm{FiO}_{2}, \mathrm{mmHg}$ & $216.74(57.38)$ & $208(64)$ & $251(41)$ & 0.099 \\
\hline Chest CT severity, n (\%) & & & & 0.531 \\
\hline Mild/moderate, $20-50 \%$ & $12(38.7)$ & $10(41.7)$ & $2(28.6)$ & \\
\hline Severe, $>50 \%$ & $19(61.3)$ & $14(58.3)$ & $5(71.4)$ & \\
\hline \multicolumn{5}{|l|}{ In-hospital outcomes, n (\%) } \\
\hline IMV & $5(16.1)$ & $5(20.8)$ & 0 & 0.187 \\
\hline Days of in-hospital stay & $7(4-11)$ & $7(4-12)$ & $7(6-9)$ & 0.661 \\
\hline Death & $4(12.9)$ & $3(12.5)$ & $1(14.3)$ & 0.901 \\
\hline
\end{tabular}

SD: standard deviation; BMI: body mass index; IQR: interquartile range; $\mathrm{PaO}_{2}$ : arterial partial pressure of oxygen; PaCO 2 : arterial partial pressure of carbon dioxide; $\mathrm{HCO}_{3}$-: bicarbonate; $\mathrm{FiO}_{2}$ : fraction of inspired oxygen; $\mathrm{CT}$ : computed tomography; IMV: Invasive mechanical ventilation; ABGs: Arterial blood gases.

suggesting that the presence of intrapulmonary shunts in mild-to-moderate COVID-19 may not correlate with a worst outcome.

This study has limitations, including the small number of recruited patients and the description of chest CT findings by the total percentage of lung damage and not by the type of radiological finding (ground-glass/ consolidation). Other limitations are that TCD was performed only on one occasion but not as a follow-up method, and that we did not include a non-COVID-19 control group. 
Figure 1. Relationship between the number of $\mathrm{HITS}$, days from symptoms onset to hospitalization, $\mathrm{PaCO}$, and $\mathrm{PaO}_{2} / \mathrm{FiO}_{2}$ ratio (A) Days from symptoms onset to hospitalization, $\mathrm{R}^{2}=0.082, \mathrm{p}=0.533$. (B) $\mathrm{PaCO}_{2}, \mathrm{R}^{2}=0.079, \mathrm{p}=0.54$. (C) $\mathrm{PaO} / \mathrm{FiO}_{2}$ ratio, $\mathrm{R}^{2}=0.328, p=0.179$. Lines show regression line from a simple linear regression with $95 \%$ confidence intervals. HITS: highintensity signals; $\mathrm{PaCO}_{2}$ : arterial partial pressure of carbon dioxide; $\mathrm{PaO}_{2}$ : arterial partial pressure of oxygen; $\mathrm{FiO}$ : fraction of inspired oxygen.

A

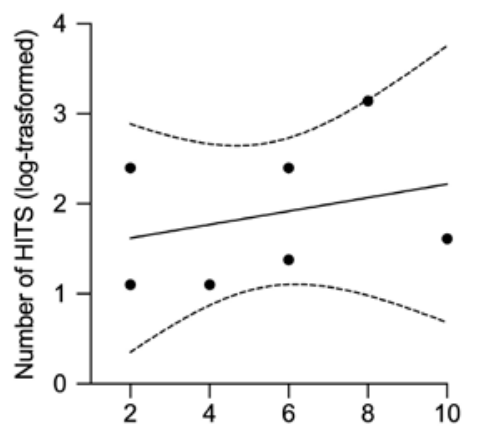

Days from symptom onset to hospitalization
B

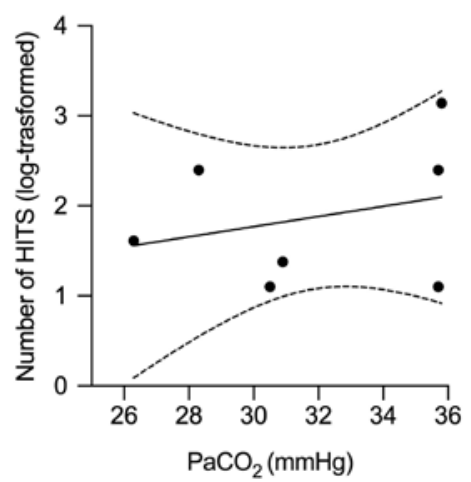

C

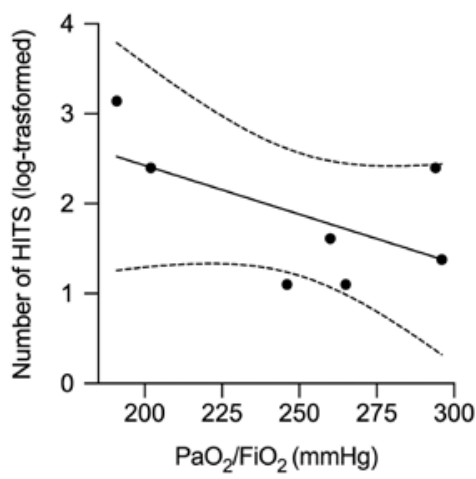

In this study we demonstrate that intrapulmonary shunting may occur in mild to moderate COVID-19, and that pulmonary vascular pathology may not play a key role until the severe stages of the disease.

\section{REFERENCES}

1. Ackermann M, Verleden SE, Kuehnel M, Haverich A, Welte T, Laenger $\mathrm{F}$, et al. Pulmonary vascular endothelialitis, thrombosis, and angiogenesis in Covid-19. N Engl J Med. 2020;383: 120-8.
2. Hariri LP, North CM, Shih AR, Israel RA, Maley JH, Villalba JA, et al. Lung histopathology in COVID-19 as compared to SARS and H1N1 influenza: a systematic review. Chest. 2020; [Epub ahead of print].

3. Patel BV, Arachchillage DJ, Ridge CA, Bianchi P, Doyle JF, Garfield $B$, et al. Pulmonary angiopathy in severe COVID-19: physiologic, imaging, and hematologic observations. Am J Respir Crit Care Med. 2020;202:690-9.

4. Mojadidi MK, Roberts SC, Winoker JS, Romero J, GoodmanMeza D, Gevorgyan R, et al. Accuracy of transcranial Doppler for the diagnosis of intracardiac right-to-left shunt: a bivariate meta-analysis of prospective studies. JACC Cardiovasc Imaging. 2014;7:236-50.

5. Reynolds AS, Lee AG, Renz J, DeSantis K, Liang J, Powell CA, et al. Pulmonary vascular dilatation detected by automated transcranial doppler in COVID-19 pneumonia. Am J Respir Crit Care Med. 2020;202:1037-9. 